\title{
Correction to: Tyrosol improves ovalbumin (OVA)-induced asthma in rat model through prevention of airway inflammation
}

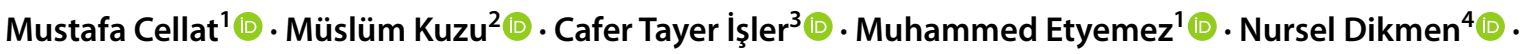

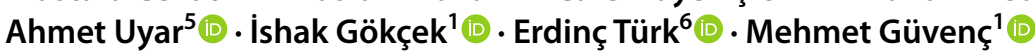

Published online: 27 September 2021

(c) Springer-Verlag GmbH Germany, part of Springer Nature 2021

\section{Correction to: Naunyn-Schmiedeberg's Archives of Pharmacology https://doi.org/10.1007/s00210-021-02117-y}

The original version of this article unfortunately contains mistakes.

Figure 4 is missing from the proof and the image used for Figure 3 in the published version was supposed to be the Figure 4 image. Below are the correct images.

This is being corrected in this publication.

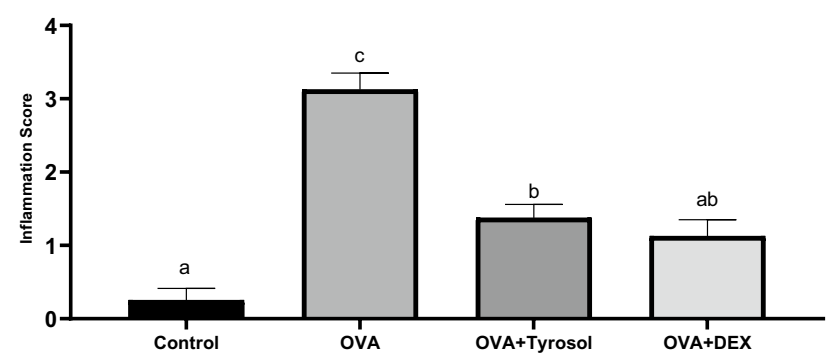

Fig. 3 Effects of tyrosol on the inflammation score of pulmonary tissues. P:0.000 Data are expressed as mean \pm SEM. Different superscript letters $(a, b, c)$ within the same column show statistically significant differences between the groups. (DEX: Dexamethasone)

The original article can be found online at https://doi.org/10.1007/ s00210-021-02117-y.

Mustafa Cellat

mcellat@mku.edu.tr; mstcellat@hotmail.com

1 Faculty of Veterinary Medicine, Department of Physiology, Hatay Mustafa Kemal University, 31060 Hatay, Turkey

2 Faculty of Health Sciences, Department of Nutrition and Dietetics, Karabük University, Karabük, Turkey

3 Faculty of Veterinary Medicine, Department of Surgery, Hatay Mustafa Kemal University, Hatay, Turkey

4 Faculty of Medicine, Department of Chest Diseases, Hatay Mustafa Kemal University, Hatay, Turkey

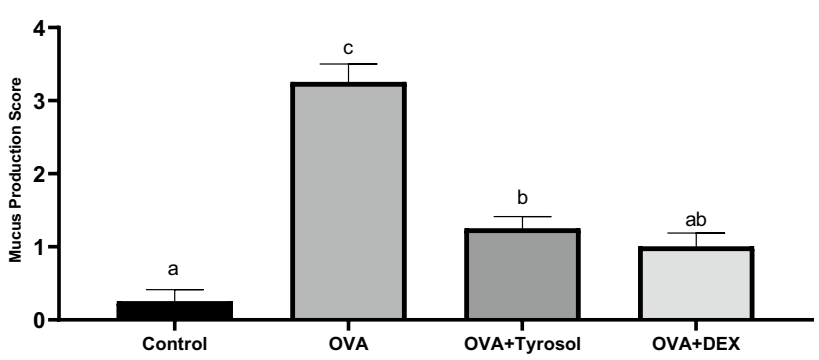

Fig. 4 Effects of tyrosol on the Mucus Production Scores (MPS) of pulmonary tissues. P:0.000 Data are expressed as mean \pm SEM. Different superscript letters $(a, b, c)$ within the same column show statistically significant differences between the groups.

Publisher's note Springer Nature remains neutral with regard to jurisdictional claims in published maps and institutional affiliations.

5 Faculty of Veterinary Medicine, Department of Pathology, Hatay Mustafa Kemal University, Hatay, Turkey

6 Faculty of Veterinary Medicine, Department of Pharmacology and Toxicology, Hatay Mustafa Kemal University, Hatay, Turkey 